\title{
LA PROPENSIÓN A APRENDER ENTRAMPADA POR LA ESCOLARIZACIÓN ${ }^{1}$
}

Propensity to learn trapped by schooling

A escolarização como cilada à propensão a aprender

Carlos Calvo Muñoz

Universidad de La Serena, Chile. Fono: +56 9 83602544. Correo electrónico: carlosmcalvom@ gmail.com

\section{Resumen}

Se aborda el sinsentido de que el ser humano dotado con el órgano más complejo de la evolución, el cerebro, fracase en la escuela. Se argumenta que la escuela está mal concebida, razón por la que las reformas no lograrán revertir los magros resultados ni las consecuencias asociadas con aquello. Se propone desescolarizar a la escuela, restituyéndole la riqueza de los procesos auténticamente educativos.

Palabras clave: propensión a aprender, escolarización, desescolarización

\begin{abstract}
It addresses the absurdity of the human being, endowed with the most complex organ of evolution, the brain, fails in school. It is argued that school is ill-conceived and this is the reason that the reforms will fail to reverse the poor results and the consequences associated with it. It is proposed to deschool the school, restoring the wealth of truly educational processes.
\end{abstract}

Keywords: propensity to learn, schooling, deschooling.

\section{Resumo}

Aborda-se a falta de sentido que há no fato do ser humano, com o órgão mais complexo da evolução - o cérebro, fracassar na escola. Argumenta-se que a escola está mal concebida, razão pela qual as reformas não conseguirão reverter os parcos resultados alcançados, assim como as consequências associadas a isso. Propõe-se desescolarizar a escola, restituindo-lhe

\footnotetext{
${ }^{1}$ Las ideas de este artículo han germinado a lo largo de la investigación FONDECYT 1110577 (2011-2014): Asombros educativos infantiles y propensión a aprender.
} 
a riqueza dos processos autenticamente educativos.

Palavras-chave: Propensão a aprender; Escolarização; Desescolarização.

\section{Propensión a aprender}

El niño propende a aprender sin límites; todo lo entusiasma y los desafíos los asume con alegría, tranquilidad y sin temor a que no podrá aprender o que lo hará mal y será sancionado por ello. Simplemente se aboca a aprender. Si durante el proceso las demandas del reto lo sobrepasan, abandonará momentáneamente la tarea para volver a ella más adelante cuando considere que se encuentra en condiciones de acometerla, aun cuando no tenga seguridad del resultado. Si vuelve a encontrar dificultades volverá a dejarla para regresar a ella hasta que logre hacerlo. Lo importante es que volverá a intentarlo. El freno inhibitorio que podría encontrar es que algún adulto le entregue la respuesta y/o le impida continuar.

El resultado poco le importa, pues le cautiva lo que puede ser; no se limita por lo que debería ser porque no lo afectan las creencias, las atribuciones, las expectativas ni las cosmovisiones que los adultos hemos creado. Su aprendizaje fluye a lo largo de procesos de creación de relaciones posibles, sin límites y con fronteras colindando con lo imposible.

Les fascina lo que es y lo que no es. La separación entre lo que es y lo que no es, que en el mundo adulto y en el de la ciencia separan en vez de unir, para ellos a lo sumo serán fronteras borrosas, pero nunca dicotómicas. "La capacidad que tienen los niños para pensar en cosas imposibles es maravillosa. [...] Cuando nuestros hijos nos bombardean con preguntas que nos parecen ilógicas, no piden ni reclaman una respuesta. No quieren cambiar el orden establecido de las cosas. Es su manera de admirarse ante una realidad que es, pero que sencillamente podría no haber sido" (L’Ecuyer, 2015:30).

Se mueven en al ámbito de la lógica trivalente, de la lógica borrosa, aquella del 'puede ser si...' o la del 'quizás sí o quizás no'. La disyuntiva les atrae tanto que optan por cualquiera de las alternativas; más tarde podrán justificar la elección si es que les parece; en caso contrario, solo se quedan con el disfrute lúdico que han vivido, incluso cuando algo no les ha resultado y hasta puede haberles hecho llorar. De este modo están atentos a como 
cambian los contextos y las circunstancias de un momento a otro. En este proceder no tiene sentido la oposición dicotómica 'sí o no', 'sabe o no sabe', porque los niños no reparan en los extremos, sino en el proceso, en aquello que 'está ocurriendo'. Siempre es sujeto activo, nunca paciente receptivo. La lógica borrosa, polivante, atribuye valor a la incertidumbre sin separarla de la vida cotidiana y del carácter procesual de todo cuanto acontece. Entre los extremos - 'sí o no'- convierte la posibilidad en probabilidad. El niño 'está siendo' o 'está jugando', siempre en proceso dinámico, siempre cambiando, sin certezas a priori y sin exclusión. Viven en un mundo abierto a las posibilidades y probabilidades.

Ellos no deciden vivir en medio de la incertidumbre ni de la ambigüedad ni en el caos, simplemente 'están siendo ocurriendo' en medio de ellos. No se trata de una opción, sino nada más que de la expresión del fluir de su 'cognición encarnada', cuya "resonancia corporal es un proceso principalmente inconsciente e invisible” (De Waal, 2011: 88). Simplemente se dejan conducir por la 'propensión a aprender', que no tiene más fin que permitirles relacionar lo que van conociendo. Parece que siempre se preguntaran '¿Qué pasaría si ...?', donde juegan a cambiar las condiciones para que ver que acontece procediendo como hacen los filósofos y los científicos (Gopnik 2010). Excepcionalmente se orientan hacia las respuestas, pues les interesa preguntar. Podríamos decir que 'están siendo lo que preguntan'.

La pregunta condicional es prodigiosa, dado que la condición no reconoce límites para la indagación de todas las infinitas posibilidades. Después vendrán las exigencias probatorias con su rigor metodológico, tal vez mucho más tarde, ya que aflorarán en el momento en que la fascinación del estudiante por lo que 'está descubriendo' se vuelva imperativa. En ese instante no rechazará esa exigencia, muy por el contrario, la agradecerá porque le ayudará a adelantar en la solución de un problema que no ha podido resolver.

La fantasía ilimitada de los niños no es el campo de la imaginación desbordada y carente de sentido, sino el campo de prueba de ideas emergentes resultado de reflexiones diversas, no siempre conscientes, pero no por ello menos válidas, pues son análogas el descubrimiento serendípico de los científicos, que les llega sorpresivamente, solo a condición de hallarse inmersos en la búsqueda de aquello de manera constante y 
sistemática. Concluir una idea novedosa no es sencillo y toma mucho tiempo de trabajo de dedicación exclusiva. Esto se nos olvida porque no acostumbramos a saber cuánto esfuerzo y confusión tuvieron aquellos de quienes estudiamos sus hallazgos como respuestas, nunca como procesos pletóricos de errores, confusiones y efímeros chispazos de claridad.

Richard Laughlin, premio nobel de Física en 1998, al presentar su libro: "Un universo diferente. La reinvención de la física en la Edad de la Emergencia" en la librería de la Universidad de Stanford, donde enseña e investiga, un niño de unos doce años le consulta cuántos borradores escribió para publicar el libro. Laughlin le responde que muchos y que todos ellos terminaron en la basura porque no servían, pero que si no los hubiera escrito jamás habría podido publicar el libro”. (2005, registro personal).

Pensar una idea novedosa difícilmente es el resultado de un razonamiento ordenado, lineal, claro y preciso, sino más bien es el fruto de razonamientos paralelos, confusos, parciales, que sorpresivamente irrumpen en la consciencia como una idea que trastorna y alegra, gracias a la cual todo se ordena 'casi instantáneamente' de acuerdo al nuevo criterio y otorgándole sentido y coherencia a muchas otras ideas que estaban dispersas y sin relación. Las estrategias que usamos para ello son diversas y pueden ser conscientes o inconscientes; de hecho, frecuentemente se nos ocurren las mejores ideas durante el sueño o en estado de somnolencia.

Einstein utilizaba mucho la alteración de sus estados de consciencia para resolver problemas de física. Tenia un diván en su estudio; se tendía en él y tenia una bola de metal en la mano y debajo un orinal, también de metal. Mientras se estaba quedando dormido, en la fase que hay entre la vigilia y el sueño, entraba en un estado alterado de consciencia (esto nos pasa a todos cuando nos vamos a dormir). Entonces la bola caía en el orinal y le despertaba, y volvía a repetirlo. Einstein contaba que los problemas más complejos los había resuelto así, en ese estado alterado de consciencia, de semi sueño. El se 'drogaba' con la dimetiltriptamina de su propia glándula pineal. Es probable que la dimetiltriptamina sea también la que genera los contenidos de nuestros sueños. (Atwell: 2015: 317)

En la neurociencia se avanza en la comprobación de que quién más experiencias ha tenido durante el día, esto es, aquella persona que más ha socializado a lo largo de la jornada, necesita dormir muchos más que el resto para que su cerebro limpie lo innecesario 
y establezca las conexiones sinápticas que le permitirán aprender de lo vivido (Lewis, 2013: 53).

\section{Relaciones posibles, probables, realizables}

En algún momento, que puede ser imperceptible para el mismo niño y niña, la curiosidad les lleva a dar un paso extraordinario cuando, al considerar todo lo que ha imaginado como posible, pondere cuáles de todas esas posibilidades tienen alguna probabilidad de suceder. Entremedio de confusiones descubrirá que lo posible tal vez jamás acontezca, pero que lo probable es aquello que tiene chance de ocurrir, que es viable o factible bajo ciertas condiciones que tratará de identificar y establecer como causas o efectos; al continuar trabajando sobre aquello la idea podría ser realizable, solo si continua dedicándole atención y esfuerzo, si bien, jamás contará con la certeza de que lo logrará, pues la incertidumbre siempre será omnipresente e inevitable.

El aprendizaje educativo es un proceso de creación de relaciones posibles, las que pueden pasar a probables si se conocen otras relaciones, gracias a las cuales podría llegar a ser realizables. En el proceso educativo el educando va de lo posible a lo probable y, de allí, a lo realizable. Dicho proceso puede ser abortado en cualquier momento por parte del aprendiente, puesto que en el trayecto las dificultades pueden desorientar, confundir, engañar y terminar desanimándolo. La importancia de un mediador que colabore es crucial; sin embargo, su ayuda debe ser de insinuación sin aplastar con explicaciones que pueden resultar incomprensibles y desmesuradas. El educando requiere de una ayuda, no de alguien que le solucione su problema. Como en todo, el sentido común servirá de guía idónea. En cada una de las etapas brotarán ideas que abrirán bifurcaciones por donde seguir. En muchos casos, solo la intuición le mostrará cuál elegir.

La tentación por proponer la respuesta correcta seducirá a muchos profesores, cuando lo mejor es que solo insinúen algún criterio para seleccionar aquellos que le ayudarán a preferir un camino entre todos los otros posibles. En este proceso jamás tendrá la certidumbre de no haber errado, sino solo grados relativos de seguridad. El proceso es riesgoso y, por serlo, mantiene al que está aprendiendo en un agradable estado de alerta. 
De niño, cansado de las preguntas que me hacían una y otra vez los comerciantes, sorprendidos de verme 'en libertad' mientras los demás niños estaban en el colegio, elaboré una pequeña frase que me presentase y zanjase de una vez por todas la cuestión: 'Buenos días, me llamo André, soy un niño, no como caramelos y no voy a la escuela. El final de la frase solía provocar cierta inquietud. Y hoy en día todavía la sigue provocando. [...] Este libro cuenta mi historia, la de un niño sin escolarizar y la del adulto en que me convertí libremente. Este libro no es un método, ni un recetario, ni una guía de anti conformismo, ni una autobiografía, sino un testimonio. Lo que se muestra en este libro es, precisamente, la multiplicidad y la individualidad de los intereses y de las maneras de aprender que la no escolarización genera. Y también ofrece la ocasión de verificar en un caso concreto si todos los males anunciados caen de verdad sobre el niño que no va a la escuela, y si se convierte, como profetizan, en un salvaje analfabeto, vegetal, asocial y aislado (Stern, 2015: 11).

El caso de Jack Andraka, quien con quince años decide crear un método de detección del cáncer de páncreas sencillo y económico, es otro ejemplo encomiable. Para conseguir un laboratorio donde poder experimentar - es decir, ver si lo posible -aquello que soñaba- era probable, escribió a más de 200 laboratorios cercanos a su casa en USA. Hay que imaginar la actitud de quienes recibieron las cartas y tuvieron que responderle. Después de muchos intentos y fracasos consiguió crear un mecanismo 400 veces más efectivo para detectar un cáncer de páncreas, ovarios y pulmón, que los existentes en el mercado farmacéutico (Andraka y Lysiak. 2015).

El caso Aidan Dwyer, de 13 años, va en el misma línea. Caminando por las montañas descubrió una nueva manera de aumentar la eficiencia de los paneles solares al recoger la luz solar (American Museum of Natural History, 2011). Lo mismo podemos decir del modo como Josh Waitzkin, aprendió ajedrez siendo niño en el Washington Square Park de Nueva York entre los trabajadores que jugaban ajedrez.

Con el tiempo, a medida que me fui convirtiendo en un miembro de 'confianza' de la escena del parque, los habituales [jugadores de ajedrez] me tomaron bajo su tutela. Me enseñaron sus trucos, a realizar devastadores ataques y a penetrar en la mente del oponente. Me convertí en un 'protegido' de la calle duro de pelar, en un competidor combativo. Era una escuela de los más particular para un niño [de 6 años]: una panda de alcohólicos, genios sin techo, apostantes adinerados enganchados al juego, fumadores de marihuana y artistas excéntricos, todos ellos diamantes en bruto, brillantes, estrafalarios, desgarbados, y con una desmedida pasión por el ajedrez (Waitzkin, 2007: 27-28).

Luego, su maestro, Bruce, depuró su comprensión y técnica: 
Bruce me serenaba con preguntas, y cuando yo tomaba una decisión importante, acertada o desacertada, me pedía que le explicara mi proceso intelectivo. ¿Había otras formas de alcanzar el mismo objetivo? ¿Había tenido en cuenta las amenazas de mi oponente? ¿Había considerado un orden de operaciones diferente? Bruce no me trataba con condescendencia. ... Cuando hacía una jugada equivocada, Bruce me preguntaba qué tenía en mente y luego me ayudaba a descubrir cómo hubiera podido afrontar de un modo diferente el proceso de toma de la decisión. Una buena parte de las clases la pasábamos en silencio, pensando. No quería darme información, sino contribuir a la maduración de mi mente por sí sola. Con el tiempo, con su forma persuasiva, humorística y firmemente mesurada, Bruce me enseñó los fundamentos de los principios esenciales del ajedrez y una comprensión sistemática de análisis y cálculo. Aunque los nuevos conocimientos eran, por supuesto, muy valiosos, el factor más significativo en aquellos primeros meses de estudio fue que alimentaba mi amor por el ajedrez, y nunca dejó que el material técnico menoscabara mi sentimiento innato por el juego (Waitzkin, 2007: 33).

Del mismo modo, André Stern, que nunca ha asistido a una escuela nos da cuenta de cómo aprendió a resolver problemas con gran pericia y calidad . "Aprendizaje y juego eran para mí sinónimos. Yo era un niño feliz y mi horario era apacible y hermoso. [...] Mis 'semanas tipo', compuestas de innúmeras actividades semanales o estructuradas y de ricas horas improvisadas, eran densas pero libres de estrés, de competitividad, de la búsqueda del rendimiento y de la pelea por la buena nota" (Stern 2015: 25). En la TV francesa le consultan: “¿Qué tal fue tu paso a la vida activa; cuando sucedió? ¿No estabas indefenso en el momento de entrar en la vida profesional, no te faltaba la experiencia del trabajo, de los demás, de los horarios fijos, etc?" a lo que responde:

... no he conocido esas diferenciaciones y esos pasos, sencillamente porque yo siempre he estado sumergido en la 'vida activa', la mía y la de los demás; no en la cápsula más o menos transparente de esa persona a la que se prepara 'por su bien', sino en el baño inmenso, multicolor, inesperado, en erupción, integralmente cosmopolita, de la simple y llana realidad. En ese gran charco, los encuentros (o incluso la confrontación) con los otros no constituyen un tema teórico, desenraizado y simplificado, explicado grosso modo con un calco proporcionado por una instancia que es parte interesada en el asunto, sino un elemento tan natural como los demás, y con el que no se negocia igual que no se negocia con los horarios. [...] No he conocido el final de los estudios y la necesidad del paso a la vida profesional. No he tenido que franquear el umbral, a veces doloroso, que separa el saber teórico -adquirido en los bancos de la escuela- de su puesta en práctica sobre el terreno: yo nunca he abandonado el terreno. Es extraño ... que ‘se preocupen’ por mí: ¿no son los 
'demás', los que se encuentran un buen día, en medio de la vida real, sin transición, sin haber conocido hasta entonces más que un mundo paralelo, un programa casi inmaterial: el estatuto escolar. [...] una tarde me encontré sobre la escena, tocando la guitarra ... (Stern, 2015: 162-163).

Estos tres chicos reconocen que siempre fueron tratados por sus padres como personas responsables y nunca minimizados como niños inmaduros con juguetes y lecturas para niños; simplemente compartían desde la niñez con los adultos y leían libros de calidad y jugaban con objetos o herramientas, como martillos de verdad. Lo mismo encontramos entre los pirahâ, que de pequeños deben aprender a sobrevivir a los peligros que acechan permanentemente en la selva amazónica:

los pirahâ hablan a los niños como a un adulto cualquiera. En la sociedad pirahâ los niños son sencillamente seres humanos, tan dignos de respeto como un adulto plenamente desarrollado. No se considera que necesiten un cuidado o una protección especial. Se les da un trato justo y se tiene en cuenta su tamaño y su relativa debilidad física, pero en general no se contempla que sean distintos de los adultos. Esto puede derivar en situaciones extrañas, incluso violentas para la mentalidad occidental. [...] Cuando un niño se corta, se quema o se hace daño con cualquier cosa, se le regaña (y también se le cuida). [...] Su manera de tratar a los niños produce adultos muy fuertes y capaces de afrontar situaciones límite, personas que no creen que nadie les deba nada. Los ciudadanos de la nación pirahâ saben que la supervivencia de cada día depende de su destreza y de su resistencia individual. [...] La percepción que tienen los pirahâ de los niños como ciudadanos iguales a todos los demás significa que no hay ninguna prohibición que se aplique a los niños y no se aplique igualmente a los adultos y viceversa. No existe, por ejemplo, el prejuicio de que los niños tienen que estarse quietecitos, calladitos y ser obedientes. Los niños pirahâ son ruidosos y bravucones y cabezotas cuando se les antoja. Tienen que decidir por sí mismos si hacen o no lo que su sociedad espera de ellos. Con el tiempo aprenden que les conviene escuchar un poco a sus padres [...] Su proceso de educación, en el que todos aprenden desde una edad temprana a cargar con su propia responsabilidad, produce una sociedad de individuos satisfechos. Esto es difícil de rebatir." (Everett, 2014: 117-119, 126, 130).

\section{Los niños y niñas amueshas nos sorprenden con otro ejemplo sobresaliente:}

En una escuela primaria fundada entre los amueshas, se organizó un concurso sobre nombres de aves. El niño vencedor ofreció 336, y ninguno de los demás escribió menos de 100. Posteriormente se les pidió que confeccionaran una lista con nombres de plantas. Uno de los niños completó 661. La nota curiosa es que los padres consideraron que sus hijos aún eran bastante desconocedores del medio rural. (Hernández, 1982: 11). 
Todos estos casos nos parecen excepcionales desde el paradigma escolar, pero no lo son cuando a los niños y niñas se les deja que propendan a aprender siendo responsables de su hacer, tal como ellos mismos reconocen. Todos ellos han vivido las tensiones propias de la búsqueda apasionada, que incluye fracasos, burla, escarnio, logros efímeros, intuiciones que sobreviven los embates fríos y, muchas veces, cargados de envidia, pero todos han seguido adelante con su sueño.

\section{Escolarización: ¿quién tiene la razón?}

La escuela goza de prestigio y reconocimiento por parte de las familias que ven en ella el mejor medio de movilidad social.

Yo no opongo la no escolarización a la escolarización. No las considero como partes contrarias que se enfrentan en un combate por puntos. ¡Yo no propongo sustituir el dogma y el programa de la escolarización por los de la no escolarización! Yo no milito en absoluto por la abolición de la escuela. Yo creo, efectivamente, que sería catastrófico, en el estado actual de las cosas, suprimirla. Pienso, efectivamente, que numerosos padres no podrían, no querrían o no sabrían de ningún modo asumir esa nueva condición: pienso, efectivamente, que la situación actual de numerosas personas haría poco realista, e incluso peligrosa, la no escolarización de sus hijos. (Andraka, 2015: 180).

Lamentablemente la escuela en muchísimas partes del mundo, especialmente donde impera la desigualdad aberrante y la marginación ignominiosa, ya no ofrece seguridad de una vida mejor que la de la pobreza abyecta y de la ignorancia opresiva. La escolaridad se ha depreciado casi totalmente; ni siquiera el haber cursado los doce años de la escolaridad obligatoria le garantizan al adolescente un sentido de satisfacción personal y colectivo por lo aprendido y por los desafíos que pudieran despertar en el aprendiente los aprendizajes logrados, ni que hablar de un trabajo seguro y bien remunerado. Se los impide el no haber aprendido a leer comprensivamente ni a calcular con convicción y confianza, entre otros aprendizajes (Maddoni, 2014).

A pesar de que el fracaso escolar de la mayoría de los estudiantes se comprueba una y mil veces sin importar el indicador que se use, la confianza en la escolarización continua siendo alta, pues se sigue esperando que gracias a ella se solucionen o, al menos, mitiguen los problemas que se generan en su exterior, cualquiera sea su origen y 
consecuencia: medio ambiente, exclusión, sexualidad, obesidad, maltrato, discriminaciones, etc. Estas peticiones desmedidas e impertinentes alteran el fluir de los procesos de enseñanza y de aprendizaje; al profesorado por sobrecargarlo con responsabilidades que corresponden a la sociedad toda y a los medios de (in) comunicación social, así como con exigencias burocráticas de control camufladas de medidas de organización didáctica; a los alumnos por aumentar la segmentación de los contenidos escolares sin puentes que los unan; a las familias que no logran ajustarse a tantas demandas escolares. Además, la pasividad reina en la mayoría de las aulas, aburriendo y estresando a profesores y alumnos, al tiempo que confunde a las familias, a pesar de todo lo que se afirma y asegura en torno a que los procesos de enseñanza y de aprendizaje sean activos.

Las culpabilidades van y vienen de parte de todos los actores. El Ministerio, muchas veces identificado con 'el sistema', se desespera buscando como garantizar la 'calidad', presionando para que los profesores enseñen todo el programa de la asignatura sobrecargada de contenidos; los profesores pidiendo dignidad, tiempo para enseñar y descansar, salario digno, alumnos motivados, entre otras demandas; los alumnos aburridos solicitando profesores que les entusiasmen para aprender y culpabilizándolos por no interesarse en lo que piensan, sienten y sueñan.

En la escuela pública de Chañaral Alto, Monte Patria, el año 1998, un alumno de $3^{\circ}$ año básico sintió curiosidad por conocer alguna palabra que reemplazara el tan usado 'presente' al momento de contestar a la lista de la asistencia. Recurrió a un diccionario donde encontró algunas palabras que fue usando a contar del siguiente día. Cuando llamaron su nombre el primer día, el alumno contestó: ‘¡asistentej'. El segundo día respondió: “iconcurrente!”. Finalmente, por tercera vez, el alumno contestó la lista diciendo: "icircunstante”. Esto fue suficiente para impacientar a la profesora y provocar un llamado de atención; además, de adjudicarse una nota de demérito (anotación negativa) en su hoja de vida. (Gómez, 2014).

Al no escuchar al alumno se coarta la propensión a aprender, corriendo el grave riesgo de que el pequeño aprenda que no puede aprender, con lo cual comienza a cerrarse el círculo de hierro de la privación cultural, que consiste en no manejar los criterios para descodificar la propia cultura. De este modo, se le empuja hacia el ostracismo académico, social y político. 
En la tradición sufi, que trabaja muy bien las paradojas, encontramos la enseñanza de Nasrudín sobre la trampa de buscar quién tiene la razón y quién está equivocado: "Se le pidió a Nasrudin que fuera el juez en una disputa entre dos vecinos. El primero presentó su caso y Nasrudin dijo: 'Yo creo que tú tienes la razón'. Luego, el segundo presentó su caso y Nasrudin dijo: 'Yo creo que tú tienes la razón'. Y un observador protestó: Pero Nasrudin, ambos no pueden tener la razón', y Nasrudin dijo: 'Yo creo que tú tienes la razón'." (McCIuggage, 1982: 94).

Si todos tienen razón en mayor o menor medida, la solución no va por encontrar cuál es la argumentación más fuerte de todas, sino que hay que buscar por rutas divergentes. La paradoja no desaparecerá gracias a las argumentaciones, pues ellas solo conseguirán profundizar en la polarización excluyente.

La lógica de la explicación conlleva el principio de regresión al infinito: la reduplicación de razones no tiene razón para detenerse jamás. Lo que detiene la regresión y le da su base al sistema es simplemente el hecho de que el explicador es el único juez del punto en que la explicación misma ha sido explicada. Es el único juez de esta pregunta, en sí misma vertiginosa: el alumno, ¿ha comprendido los razonamientos que le enseñan a comprender los razonamientos? Y ahí el maestro sostiene al padre de familia: ¿cómo este podría estar seguro de que el niño ha comprendido los razonamientos del libro? (Rancieère, 1987: 19).

\section{Crisis del paradigma escolar}

Es un contrasentido absurdo que el ser humano, que posee el órgano más complejo de la naturaleza, el cerebro, que evolucionó a lo largo de millones de años para permitirle aprender, fracase en la escuela y se le culpe duramente, se incrimine a la familia, al profesorado, al sistema, aduciendo razones diversas, que no por ciertas, son la causa basal. Consideramos que el meollo está en el paradigma con el que está concebida la escuela que no favorece que fluya la propensión a aprender connatural al ser humano. Tal como está concebida la escuela no será posible revertir los magros resultados.

Urge, por lo tanto, que la comunidad educativa responda 'cómo es posible que exista el fracaso escolar de manera masiva si estamos dotados para aprender'. 
Afirmamos que el embrollo actual que enreda y daña los procesos de enseñanza y de aprendizaje al interior de la escuela y que subyace a la organización escolar en toda su complejidad está paradigmáticamente errada. Resolver la encrucijada es prioritaria, ya que los cambios introducidos al sistema son pocos, casi irrelevantes y con mínima continuidad en el tiempo, con lo cual se daña casi irremediablemente a millones de jóvenes. Revertir los daños es frustrante, descalificador y enormemente costoso.

Las dificultades que encuentran los maestros para poder enseñar son multicausales; sin embargo, entre todas ellas la única que no se puede renovar poco a poco, como sucede con un aumento salarial o con la disminución del número de alumnos por sala o con los contenidos curriculares, es la concepción escolarizada que predomina hegemónicamente en la escuela, pues se trata de un asunto paradigmático, que se encuentra imbricado en la cosmovisión cultural de toda la sociedad que incluye valores, creencias, convencionalismos, estereotipos, etc.

La concepción cartesiana del 'pienso, luego existo' y el positivismo científico avasallan en el 'ethos cultural'. La escolarización deviene un proceso netamente cerebral, donde el cuerpo es marginado, si no, excluido; por ejemplo, por años no se ha sabido que hacer con las clases de educación física, las que, gracias a las evidencias a su favor, han ido ganando su lugar, aunque sigue siendo marginal, especialmente frente a la enseñanza de las matemáticas y del lenguaje. También han sido confinados los sentimientos, las emociones y la subjetividad en pos de alcanzar la objetividad, que alborota todos los procesos evaluativos con sus indicadores supuestamente neutros. Se confunde subjetividad con arbitrariedad e injusticia, sin reparar que es gracias a la valoración subjetiva que podemos pretender ser ecuánimes, pues solo ella nos ayudará a justipreciar los antecedentes y las distintas circunstancias en juego en los procesos evaluativos.

La aspiración a la objetividad lleva a dicotomizar entre polos mutuamente excluyentes - el alumno sabe o no sabe- y no a una dualidad donde la oposición sea complementaria, gracias a la cual la ignorancia no será excluyente del saber sino una de sus tantas expresiones momentáneas y condición necesaria para la gestación de preguntas emergentes, algunas de las cuales se podrán formular de manera clara, mientras que muchas 
otras demorarán en germinar en la conciencia y otras que nunca conoceremos pero que nuestro inconsciente trabajará en ellas hasta que puedan aflorar como intuición.

Hay que recuperar lo simple para encontrar la rica complejidad de todo cuanto nos rodea. Wilson, el mirmecólogo, especialista en hormigas, en "Cartas a un joven científico" afirma que los fundamental es el entusiasmo: "Primero pasión, después preparación". (Wilson, 2014: 29). Obviamente que no desdeña el estudio responsable y metódico, que garantiza conocimientos fiables e inequívocos, pero los instala después de la pasión. La pasión sin la subjetividad se vuelve estéril; la preparación sin la objetividad deviene ineficaz. La pasión y la preparación deben acompañarse con la ética del trabajo. Sin ellas, no se podrá alcanzar la excelencia.

Ser brillante no es suficiente para los que sueñan con el éxito en la investigación científica. La fluidez en matemáticas no es suficiente. Para alcanzar la frontera y permanecer en ella, es absolutamente esencial una fuerte ética del trabajo. Tiene que haber una capacidad para pasar largas horas de estudio y trabajo con placer, aunque parte del esfuerzo conduzca inevitablemente a callejones sin salida. Este es el precio de la admisión en la primera fila de los científicos investigadores. (Wilson, 2014: 88-89).

En estos últimos años en Japón las escuelas públicas ofrecen a sus estudiantes mucho más tiempo libre que antes, pues reconocen que estudiar más no funciona, pues deben tener más tiempo para pensar (Holt, 2002); se trata de un tiempo no estructurado, "aunque sus jornadas escolares son más largas y sus alumnos sacan mejores notas, un 25 por ciento de la jornada escolar de los niños asiáticos consiste en un tiempo no estructurado." (Brafman y Pollack, 2014: 70-71). De hecho, durante el tiempo no estructurado, como sucede en el recreo, aumenta la eficacia porque cuando una persona está sin hacer ninguna actividad (momento en que se supone que el cerebro está descansando) se activan un sinfín de mecanismos que mantienen al órgano completamente activo, por lo que la persona puede estar realizando muchas tareas simultáneamente. (Smart, 2014).

La escuela tampoco favorece el mejor desempeño pues con frecuencia los grupos se adaptan a lo que los otros están haciendo.

Maximilian Ringelmann, un ingeniero francés, investigó en 1913 el rendimiento de los caballos. Descubrió que el rendimiento de dos animales de tiro enganchados juntos a un carruaje no 
es el doble que el rendimiento de un único caballo. Sorprendido por este resultado, amplió su investigación a la gente. Hizo que varias personas tiraran de una cuerda y midió la fuerza que cada uno aplicó. De media, las personas que tiraban en pareja invertían el 93 por ciento de la fuerza de un único tirador; si tiraban de tres en tres, era del 85 por ciento; y en grupos de ocho, solo el 49 por ciento. Aparte de sorprender a los psicólogos, este resultado no sorprende a nadie. La ciencia lo denomina 'pereza social' (social loafing). Aparece donde el rendimiento del individuo no es directamente visible, sino que se diluye en el grupo. Hay pereza social en el remo, pero no en los relevos, porque en este caso las contribuciones individuales son públicas. La pereza social es un comportamiento racional: ¿por qué invertir toda la fuerza si con la mitad es suficiente sin que se note? En resumen, la pereza social es una forma de engaño que nos hace culpables a todos, por lo menos, no intencionadamente. El engaño se desarrolla inconscientemente, como en el caso de los caballos. Lo sorprendente no es que el rendimiento individual retroceda cuanta más gente tira de una cuerda. Lo sorprendente es que no caiga a cero. ¿Por qué no una pereza total? Porque un rendimiento cero llamaría la atención con todas sus consecuencias, Como la expulsión del grupo o el descrédito. (Dobelli, 2011: 143-144).

Por otra parte, cada vez más personas reparan en las contradicciones que implica el modelo paradigmático de la escuela en donde 'más es menos', por lo que abogan por un cambio radical donde 'menos sea más'. En “Elogio de la educación lenta”, se nos sugieren algunos principios (Domènech, 2009:81-82):

- La educación es una actividad lenta.

- Las actividades educativas han de definir su tiempo y no al revés.

- En educación menos es más.

- La educación es un proceso cualitativo.

- El tiempo educativo es global e interrelacionado.

- La construcción de un proceso educativo debe ser sostenible.

- Cada niño y cada persona necesita su tiempo para el aprendizaje.

- Cada aprendizaje debe realizarse en su momento.

- Para conseguir aprovechar mejor el tiempo, hay que priorizar y definir las finalidades de la educación. 
- La educación necesita tiempo sin tiempo.

- Hay que devolver tiempo a la infancia.

- Debemos repensar el tiempo de las relaciones entre adultos y niños.

- El tiempo de los educadores debe redefinirse.

- La escuela ha de educar el tiempo.

- La educación lenta forma parte de la renovación pedagógica.

Una vía es simplificar la complejidad, evitando, por supuesto, caer en la superficialidad y la complicación. Todo es complejo y no es posible disminuirlo; sin embargo, la vía para tratar con la complejidad en los procesos educativos, no escolarizados, es estableciendo criterios que permiten simplificar la información. La falta de criterios lleva a superficializarla y a no dar importancia a los misterios que encierra. La explicación superficial, a su vez, lo único que hace es generar complicadas marañas donde todos se confunden.

\section{Tentación de la escolarización}

Las complejas exigencias sociales actuales, exacerbadas por el modelo el neoliberal, lleva a trastornos enredados y a espejismos cándidos respecto a qué esperar de la escolarización. Una de aquellas quimeras, que ha enraizado profundamente en muchos padres y madres es de esperar que sus hijos se conviertan en genios sobre estimulándolos con programas especiales, como el "efecto Mozart", "Baby Eisntein” y otros, olvidando que la propensión a aprender fluye a la par que los procesos naturales y que esos programas no son necesarios. A los pequeños hay que dejarles que experimenten.

Los niños tienen una afinidad natural con la naturaleza. ... La naturaleza hace que los niños sean capaces de mantener la atención durante horas mirando las plantas, los insectos y jugando con el barro y el agua. Recientes estudios demuestran que el juego en entornos naturales reduce los síntomas de déficit de atención en algunos niños. La naturaleza permite a nuestros hijos encontrarse con la realidad en estado puro, les enseña que las cosas no son inmediatas y que lo bueno y lo bello llevan su tiempo. Esto favorece que sean unas personas capaces de controlar su impulsividad, fuertes, 
pacientes y capaces de aguantar con menos ahora para tener más después ..., una cualidad que sin duda escasea hoy en día en los niños y los jóvenes. (L’Ecuyer, 2015:92-93).

Es curioso como la cultura escolar obliga a comportamientos que no usamos en la vida diaria. ¿Existe acaso alguna actividad infantil no escolarizada en la que los pequeños para aprender permanezcan sentados por períodos largos que los obligan a la inmovilidad y al silencio, cuando lo que ellos siempre hacen es moverse, brincar, saltar, preguntar, experimentar? En la naturaleza no hay nada parecido a la iglesia o a la escuela. ... No hay ningún 'árbol maestro' que ordena y le diga a los árboles jóvenes como deben crecer” (Zeledón, 2007: 187).

A pesar de ello, la escolarización enclaustra en espacios cerrados y en tiempos cada vez más escasos para llenar al estudiante con información que no alcanza a procesar. Se ignora que "nuestro cerebro necesita espacio en blanco para pensar creativamente". (Brafman y Pollack, 2014: 61).

Hemos propuesto que los programas escolares se reduzcan hasta en un 50\%, de tal modo que los profesores y estudiantes 'tengan tiempo' para enseñar y aprender con calma, en clases más cortas, con más descansos reales entre una clase y la otra, para no caer en las presiones del agobio escolar, por ejemplo. Entre otras tareas hay que recuperar el valor educativo del recreo donde

los tipos de interacciones sociales que mantienen los niños unos con otros durante el recreo, a menudo sin que participe en ellas un adulto, son más complejas y socialmente más enriquecedoras que las interacciones que mantienen bajo la dirección de un docente. Las habilidades que adquieren los niños en este espacio en blanco, a su vez, les ayudan a desarrollar su capacidad cognitiva [...] Aprender a moverse en el ámbito social por su cuenta, durante el recreo, ayuda a los niños a desarrollar el pensamiento complejo y a gestionar mejor el estrés. [...] Los niños pequeños que salen a recreo se enfrentan al reto de las demandas sociocognitivas que no tienen lugar en el aula. Es más probable que los niños estén en desacuerdo unos con otros dentro del caos relativo y social del recreo que no discrepen del maestro en el entorno estructurado del aula. Cuando discrepan, se enfrentan al punto de vista de otra persona. Se ven obligados a intentar comprender la perspectiva de sus amigos, y enfrentarse a las consecuencias. De la misma manera que los niños deben aprender matemáticas y a leer, también necesitan aprender cómo funcionar en entornos sociales, cuando no tienen tareas. Durante el recreo, los niños aprenden cosas como decidir a qué jugar, elegir a un líder de juegos, resolver conflictos y encontrar maneras de interactuar con otros. En tales entornos desestructurados tiene lugar una parte sorprendente de culturización social. De hecho, cómo les vaya a los niños en el patio de juegos es un buen indicador de cómo les irá en la escuela. Es importante destacar que los 
investigadores no proponen una jornada escolar sin un plan lectivo o normas. No sugieren que el caos dure todo el día (lo cual en ocasiones cuesta evitar en una escuela primaria). No, lo que sugieren es que se introduzcan unidades discretas de tiempo desestructurado (reductos discretos de caos) durante el día, para ayudar a los alumnos a aprender mejor. (Brafman y Pollack. 2014: 77, 79-80).

\section{Desescolarización de la escuela}

Desescolarizar la escuela es simple: basta quitarle todo lo que tiene de escolar para que la educación vuelva a imperar en ella. Si educar consiste en el proceso de creación de relaciones posibles, probables y realizables, la escolarización se reduce a repetir relaciones pre-establecidas (Calvo, 2013). El proceso educativo fluye naturalmente gracias a la propensión a aprender, que discurre hacia la búsqueda de regularidades que, más adelante, buscará organizarlos como patrones de acuerdo a ciertos criterios emergentes. Igualmente brotarán, quién sabe de dónde, bifurcaciones que complejizan en grado sumo lo que se está aprendiendo. El educando creará relaciones provisorias y equívocas, que se pondrán a prueba para ver si son consistentes y permanentes. Durante el mismo proceso va tomando forma la necesidad de nombrar lo que se va descubriendo, para lo cual el educando buscará cuáles serán las palabras más adecuadas; si no las encuentra podrá crear neologismos hasta que halle la más adecuada y precisa.

La palabra escolarizada pierde su fuerza, su capacidad de decir alguna cosa. Como la pierde también el mundo escolarizado y la vida escolarizada. Por eso, de lo que se trata es de inventar formas de desdisciplinar las disciplinas, de desescolarizar las palabras, los textos, las formas de leer y de escribir, las formas de conversar, para que puedan recuperar su capacidad de encarnación, su viaje azaroso, su potencia de vida. Y, para ello, hay que inventar formas de desescolarizar a los alumnos, de desalumnizarlos, y de desescolarizarnos a nosotros mismos, de desprofesorizarnos, para poder poner en juego, ellos y nosotros, otras relaciones con el lenguaje, con el mundo y con ellos mismos. (Larrosa, 2012: 24-25).

Todo este proceso que fluye solo en términos educativos, se aborta en las escuelas si el educando encuentra descrito los procesos, las palabras y la importancia de lo que está aprendiendo, pues se le ha quitado la curiosidad, el entusiasmo y los desafíos, que son los aspectos primordiales para que fluya la propensión a aprender.

Para favorecer el discurrir de la propensión a aprender y avanzar hacia la 
desescolarización de la escuela hay que recuperar el valor de la palabra, encarnarla en el vivir cotidiano, en el desafío de investigar, en el asombro que nos deja perplejos ante lo que todavía no podemos nombrar. De este modo, la palabra renombrará lo educativo que subyace en la cultura escolar. "Desescolarizar las palabras y desalumnizar a los alumnos es, indisolublemente, desprofesorizarnos como profesores". (Larrosa, 2012: 26).

Desde una perspectiva educativa ningún proceso vuelve a repetirse porque jamás discurrirá de la misma manera en una segunda oportunidad; por el contrario, desde una mirada escolarizada, se asume que los procesos serán más o menos iguales y que sus diferencias son descartables. Esto no es así y ya está suficientemente bien documentado la influencia que una pequeña perturbación ejerce en el desarrollo de cualquier proceso. El matemático y meteorólogo Lorenz acuñó la expresión 'efecto mariposa' para dar cuenta de que el pequeño e insignificante aleteo de una mariposa puede cambiar el clima al otro lado del mundo.

Es frecuente que la planificación escolar no considere que una pequeña perturbación inicial tiene efecto amplificador durante el proceso de tal modo que este siga un curso completamente diferente del que se esperaba. La planificación escolar es necesaria, pero para la realización de la clase el profesor debería quemarla simbólicamente al ingresar al aula, como una manera de establecer que los profesores y los alumnos participarán en una clase donde improvisarán en la búsqueda de la creación de relaciones inéditas, ayudado por la adrenalina ante el desafío de lo imprevisto, que se mueve en una tensión constante entre 'orden y caos'. Solo puede improvisar el que sabe. Esto lo conocen muy bien los bailarines, deportistas, científicos, cirujanos, conductores, cocineros, en fin, todo aquel que posee destrezas y conocimiento sobre un aspecto del saber.

Esta tensión une el ser y el estar de todos los actores de los procesos educativos, pues en ellos, el educador educando y el educando educador (Freire) 'están - siendo aprendiendo’. En este sentido, el educador no enseña, sino que cuestiona genuinamente lo que está mostrando, gracias a lo cual 'aprende algo inédito' en su experiencia. Lo que aprende puede ser nada más que una duda pequeñita, ínfima, casi imperceptible, y que solo se da cuenta si está atento a ella, pero de efectos inimaginables si se trata de una idea 
germinal. La atención, sin embargo, no es obsesiva, sino relajada como si se estuviera atento a otra cosa, pues de esa manera atiende mejor a los detalles. Es serendípica.

Para desescolarizar la escuela hay que predisponerse y estar atento ante lo distinto y no solo prestar atención a lo previsible, a las causas que explican los efectos, que no es más que el objetivo de la ciencia. También hay que atender a las coincidencias y a las relaciones causales, que podrían manifestarse en lo fortuito, accidental o casual, es decir, en lo no anticipable, aunque pudiera ser previsible. Es importante planificar la 'casualidad', evitar la seducción de los datos y las mediciones, y confiar en que el caos tiende inevitablemente al orden, aunque sea un orden que nos confunda o nos fastidie porque no es lo que anticipábamos. (Brafman y Pollack, 2014).

La emergencia inesperada, si bien en algunas ocasiones nos distrae, en otras es lo único que nos ayuda a encajar una idea en un contexto más amplio. Se ha acuñado la expresión 'spacing effect' para dar cuenta de que se aprende más y se retiene aquello por más tiempo, cuando los períodos del estudio se distribuyen en momentos diferentes, a que cuando se concentra en períodos intensivos. (Carey, 2014).

Esto me hace pensar en como fluye la propensión a aprender en los pequeños que picotean de un tema a otro, como si no prestaran atención a lo que están haciendo, pero siempre vuelven al punto de partida para volver a comenzar otra circunnavegación.

\section{Referencias bibliográficas}

American Museum of Natural History (2011). Young Naturalist Award Winners 2011.pdf (http://www.amnh.org/about-us/press-center/2011-young-naturalist-award-winners).

Atwell, B. (2015). El advenimiento de la noosfera. En Prima, F. (Coord.). Nuevos Paradigmas. Entrevistas con Lynne Mctaggart, Nassim Haramein, Jean-Pierre Garnier Malet, Alfred L. Webre, J.Z. Knight, Dean Radin, Alberto Arribalzaga, Juan I. López Martinez, Emilio Carrillo, Drunvalo Melchizedek, Anne Givaudan, Gregg Braden, Patrick Drouot, Howard Bloom, Bianca Atwell, Elisabet Sahtouris, Matthias Rath, Ghislaine Lanctcadt, Luz Angela Carvajal. Málaga: Editorial Sirio. Pp.: 307-323. 
Brafman, O. y Judah P. (2014). La necesidad del caos. Cómo el riesgo y lo disruptivo incrementan la innovación, la afectividad y el éxito. Barcelona: Empresa Activa.

Calvo, C. (2013, 5 ed.). Del mapa escolar al territorio educativo: disoñando la escuela desde la educación. La Serena: Universidad de La Serena.

Carey, B. (2014). How we learn. The surprising Truth About When, Where, and Why It Happens. New York: Random House.

De Waal, F. (2011). La edad de la empatía. ¿Somos altruistas pro naturaleza? México: Tusquets Editores

Dobelli, R. (2011). El arte de pensar. 52 errores de lógica que es mejor dejar que cometan otros. Bogotá: Ediciones B.

Domènech, J. (2009). Elogio de la educación lenta. Barcelona: Editorial Graó.

Everett, D. (2014). 'No duermas, hay serpientes'. Vida y lenguaje en la Amazonía. Madrid: Turner Publicaciones.

Gómez, I. (2014). Alumno de Derecho, UCEN, La Serena, y cajero casino central, Universidad de La Serena. Carta personal. Documento sin publicar.

Gopnik, A. (2010). How do babies think? Scientific American, 1: 76-81.

Hernández, I. (1982). Conciencia étnica y educación indígena. Punta de Tralca: Taller sobre Teoría y Política de la Educación Popular: FLACSO, PHE, IDRC, Fundación Ford; marzo.

Holt, M. (2002). It's Time to Start the Slow School Movement. Phi Delta Kappan, 84, 4: 264-271.

Larrosa, J. (2012). Fin de partida. Leer, escribir, conversar (y tal vez pensar) en la universidad que viene. Bogotá: Babel Libros.

Lewis, P. (2013). The secret world of sleep. The surprising science of the mind at rest. New York: Palgrave Macmillan. 
Maddoni, P. (2014). El estigma del fracaso escolar. Nuevos formatos para la inclusión y la democratización de la educación. Buenos Aires: Paidos.

McCIuggage, D. (1982). El esquiador centrado. Santiago de Chile: Editorial Cuatro Vientos.

Smart, A. (2014). El arte y la ciencia de no hacer. Madrid: Clave Intelectual.

Stern, A. (2009). Yo nunca fui a la escuela. Albuixech (Valencia): Litera libros.

Waitzkin, J. (2007). El arte de aprender. Un viaje en busca de la excelencia. Barcelona: Urano.

Wilson, E. (2014). Cartas a un joven científico. Santiago de Chile: Debate.

Zeledón, C. (2007). De Einstein a Castañeda. La magia a la luz de la ciencia. México: Editora Alba. 